\title{
Numerical Simulation of the Relationship between the Width of Destressed Zone and Blasthole Depth
}

\author{
Jiansheng Tian, Qingru Wu, Zhijun Liu \\ School of Mechanics \& Civil Engineering, China University of Mining \& Technology, Xuzhou, China \\ Email: tianjs2978@163.com
}

How to cite this paper: Tian, J.S., $\mathrm{Wu}$, Q.R. and Liu, Z.J. (2020) Numerical Simulation of the Relationship between the Width of Destressed Zone and Blasthole Depth. Engineering, 12, 269-279. https://doi.org/10.4236/eng.2020.124022

Received: March 18, 2020

Accepted: April 21, 2020

Published: April 24, 2020

Copyright $\odot 2020$ by author(s) and Scientific Research Publishing Inc. This work is licensed under the Creative Commons Attribution International License (CC BY 4.0).

http://creativecommons.org/licenses/by/4.0/

\section{(c) (i) Open Access}

\begin{abstract}
Overstress in the surrounding rock of the roadway is a key reason that causes failures of deep roadways. Destressing blasting is one of the promising techniques that could improve the supporting quality. If the depth of the pressure relief blast hole is too shallow, the surrounding rock of the roadway will be broken or even collapsed. If the pressure relief blast hole is too deep, the pressure relief area will be located in the deep part of the surrounding rock of the roadway, which cannot achieve the purpose of releasing the stress in the shallow part of the surrounding rock and cause waste of the blast hole. The width or range of the pressure relief area should just fall in the high stress area of the surrounding rock of the roadway, so the pressure relief blast hole should have a reasonable depth. In order to quantitatively describe the relationship between borehole depth and the width of the stress relief zone, numerical simulations were carried out in ANSYS according to different borehole depths. The results show that the optimal destressing effect is achieved when borehole depth is $4 \mathrm{~m}$. Peak stress of $\sigma_{\theta}$ and $\sigma_{\gamma}$ is significantly reduced by $30.51 \%$ and $49.07 \%$ after blasting. Meanwhile, the high-stress area shifts about $4.8 \mathrm{~m}$ from the roadside to the depth of surrounding rock, thus a $3.8 \mathrm{~m}$ wide stress relief zone is formed around the roadside, thus, the aim of quantizing the effects of destress blasting is achieved.
\end{abstract}

\section{Keywords}

Rock Burst, Deep Roadway Supporting, Width of Stress Relief Zone, Destress Blasting, Numerical Simulation

\section{Introduction}

With the increase of mining depth, traditional means have been unable to solve 
the problems of deep roadway supporting [1], thus roadway supporting is confronted with serious challenges. Destress blasting, the main method widely used for the control and prevention of pressure bump, is an active approach to lower the frequency of rock burst [2]-[13]. In order to reduce the difficulties of deep roadway supporting and enhance the quality of supporting, this paper adopts destress blasting to improve the stress state of shallow surrounding rock and lower its stress level.

Regarding research on deep roadway supporting, theoretical analysis, numerical modeling, and field monitoring methods have been utilized to study the effect of destress blasting. The small deflection theory of elastic thin plate and numerical simulation has been used by Zhao S.K. et al. [14] to analyze the roadway floor stress condition, it has been found that the mining horizontal stress is the key reason for floor heave, when the position of blasting holes is in the middle of the floor and roadway center line, the prevention effect gets more apparent. Tian and Jing's research [15] utilizes the theory of confined blasting to systematically analyzes how destress blasting in a soft-rock tunnel can relieve pressure in the rock and its influencing factors, it shows that destress blasting hardens soft rock and transfers geo-stress to the depth of the surrounding rock, their research also points out that the width of pressure released zone is the key to evaluate the blasting effect, and the width of pressure released zone is also closely related to the depth of blast holes. In Chen et al.'s research [16], the destress tunnel model was studied using holographic static photo-elastic experimental system in different surrounded stress when blasting occurred in tunnel's sides, it shows destress blasting betters the stress state of surrounding rocks. Researches of Gao et al. [17] and Zhang et al. [18] present that destress blasting reduces the stress of the surrounding rock which helps maintain the stability and safety of the high stressed surrounding rock. Both Zhang Ping's [19] and Zhao Gan's [20] researches perform experiments by adopting the way of bolting and destress blasting to repair the roadway, their experiments indicate that destress blasting improves the stress state of the surrounding rock and reduces the stress acting on the supporting structure. In Guo's and Wang's study [21], the surrounding rock stress is monitored and the supporting performance before and after blasting is analyzed, it shows destress blasting transfers the peak stress and changes the distributing regulation of surrounding rock stress field.

At present, destress blasting has become an essential means which is widely applied in practice among the deep roadway supporting for its effectiveness in increasing the roadway supporting quality. However, a great number of practical applications are still based on experience, thus how to make the destress blasting optimum is not sure. There is still no quantitative concept of some problems such as how much can destress blasting reduce the stress level of surrounding rock, how widely can destress blasting form the destressed zone in the shallow surrounding rock and how far can destress blasting transfer the high stress to the depth of rock away from laneway's side.

In order to obtain the quantitative conclusion of the effect of unloading blast- 
ing in the deep tunnel, further the understanding of the nature of destress blasting and provide the professional guidance, this paper investigates relationships between the changing depth of blast holes and the effect of unloading blasting by using numerical simulation method.

\section{Numerical Models and Parameters}

\subsection{Yield Criterion}

In this paper, ANSYS is adopted to simulate the destress blasting's effect on roadway surrounding rock. In order to set up the numerical simulation, firstly, the element type of roadway rocks should be confirmed. Considering deformation characteristics of roadway surrounding rock, SOLID65 is selected for its properties of tension crack, crush, plastic deformation and creep.

Secondly, yield criterion of roadway surrounding rock should be confirmed. Present yield criteria for geotechnical materials roughly includes Von Mises yield criterion, Mohr-Coulomb yield criterion, Drucker-Prager (D-P) criterion et al. Among them, D-P criterion can describe the deformable features of rock and concrete more accurately [22]. Thus, D-P yield criterion is selected in the simulation to judge when roadway-surrounding rock starts to yield under the complex stress condition. Materials using the D-P yield criterion are referred to as D-P materials for short.

In the data table of ANSYS's options for D-P material, numerical values of cohesion $C$, internal friction angle $\varphi$, dilatancy angle $\varphi_{f}$ need to be typed in. Dilatancy angle $\varphi_{f}$ is used to control the size of volume expansion. The compacted granular material will dilate when it is in shear. If $\varphi_{f}=0$, the volume will not dilate, if $\varphi_{f}=\varphi$, all materials' volume will dilate seriously. In general, $\varphi_{f}=0$ is a conservative approach.

The compressive yield strength of D-P material is much higher than its tensile yield strength. When uniaxial compressive stress and uniaxial tensile stress are known, internal friction angle $\varphi$ and cohesion $C$ can be expressed as:

$$
\begin{gathered}
\varphi=\sin ^{-1}\left(\frac{3 \sqrt{3} \eta}{2+\sqrt{3} \eta}\right) \\
C=\frac{\sigma_{y} \sqrt{3}(3-\sin \varphi)}{6 \cos \varphi}
\end{gathered}
$$

The relationship between $\eta, \sigma_{\gamma}$ and compressive stress, tensile stress are as follows:

$$
\begin{gathered}
\eta=\frac{\sigma_{c}-\sigma_{t}}{\sqrt{3}\left(\sigma_{c}+\sigma_{t}\right)} \\
\sigma_{y}=\frac{2 \sigma_{c} \sigma_{t}}{\sqrt{3}\left(\sigma_{c}+\sigma_{t}\right)}
\end{gathered}
$$

For the D-P model, its equivalent stress $\left(\sigma_{e}\right)$ formula is: 


$$
\sigma_{e}=3 \xi \sigma_{m}+\left[\frac{1}{2}\{S\}^{T}[M]\{S\}\right]^{1 / 2}
$$

where $\{S\}$ is deviatory stress. $[M]$ is determined according to the following equation of modified yield criterion which considering the effect of mean stress $\sigma_{m}$. This modified yield criterion can be used to determine whether the rock is in an elastic state or a plastic state.

$$
F=3 \xi \sigma_{m}+\left[\frac{1}{2}\{S\}[M]\{S\}\right]^{1 / 2}-\frac{6 C \cos \varphi}{\sqrt{3}(3-\sin \varphi)}=0
$$

Mean stress $\sigma_{m}$ is determined according to:

$$
\sigma_{m}=\left(\sigma_{x}+\sigma_{y}+\sigma_{z}\right) / 3
$$

Material constant $\xi$ is determined according to:

$$
\xi=\frac{2 \sin \varphi}{\sqrt{3}(3-\sin \varphi)}
$$

\subsection{Basic Hypothesis}

The stress condition of roadway surrounding rock under blasting is extremely complicated. It is necessary to simplify the numerical model appropriately so that the key problem can be studied.

Thus following basic hypotheses are proposed:

1) The burial depth of roadway is $800 \mathrm{~m}$, and the underground stress field is under uniform loading.

2) The roadway is treated as a plane strain problem for its length is longer than its span.

3) Roadway surrounding rock is modeled as isotropic homogeneous continuous medium.

4) The effect of factors like deflection rate, temperature to stress and strain is ignored, and the time effect of resilience and creep is also ignored.

\subsection{Calculation Modeling}

In order to study the deformation law of roadway surrounding rock after blasting, the cross section of roadway is set as rectangular whose size is $4 \mathrm{~m} \times 3 \mathrm{~m}$. The maximum dimension of calculation model is about 5 times larger than the roadway width. According to the symmetry, half of the roadway is used to establish the calculation model. The size of model plane is $20 \mathrm{~m} \times 15 \mathrm{~m}$, the thickness of model is determined according to the simulation scheme. The element type of rock is SOLID65. The blasting hole is perpendicular to roadside. It is $1.5 \mathrm{~m}$ away from roadway floor and is arranged uniformly along the roadway. The blast hole adopts non-coupling charging structure. The numerical simulation model is shown in Figure 1

\subsection{Parameters of Boundary Conditions and Mechanical Models}

Boundary conditions are applied to the numerical simulation according to stress 


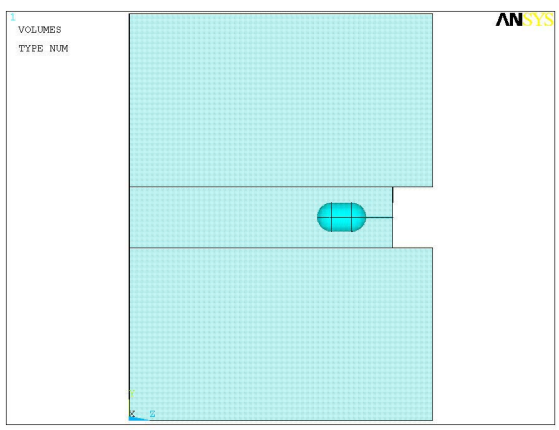

(a)

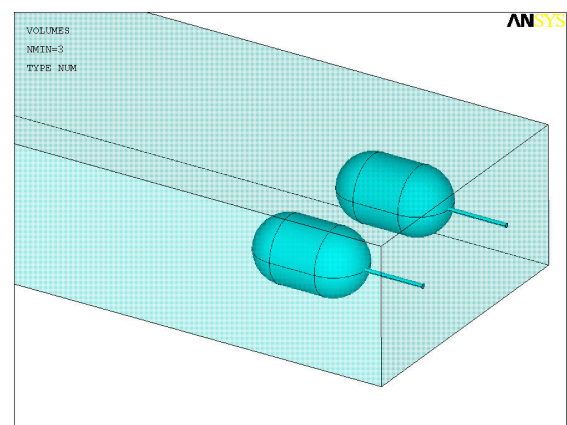

(c)

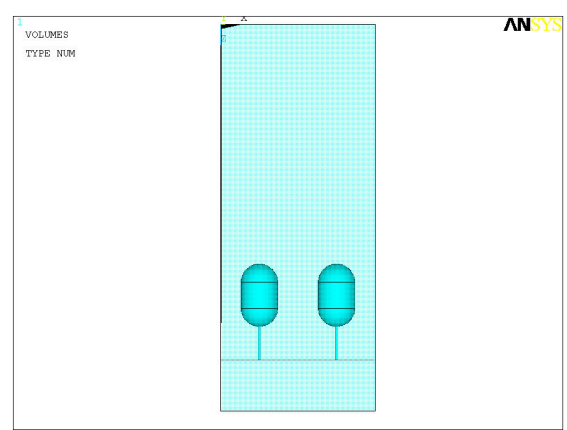

(b)

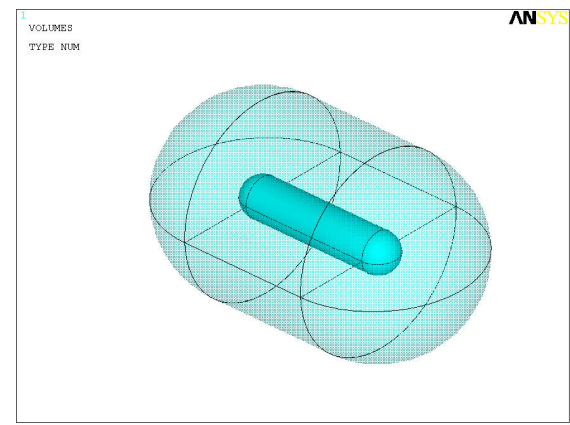

(d)

Figure 1. Schematic diagram of numerical model. (a) Front view; (b) Top view; (c) Orthographic view of the damage zone; (d) Smash zone and fractured zone.

and displacement. All boundaries including the left boundary, the right boundary, the front boundary and the back boundary of the model are single constraint. Displacement constraint applied to the model is horizontal direction. The bottom of model is set as multiconstrained boundary. Both of the horizontal displacement and vertical displacement of boundary nodes are all zero. According to the buried depth of roadway and Heim's Hypothesis, the load applied to the top of model is overburden stress.

Surrounding rock's properties and mechanical parameters adopt the datum from the gate road of fully mechanized face in one mine (Table 1). Destress blasting zone's weakening method is based on the research [23]. Safety explosive, whose density is $1000 \mathrm{~kg} / \mathrm{m}^{3}$, detonation velocity is $3500 \mathrm{~m} / \mathrm{s}$, is adopted in the simulation.

\subsection{Numerical Simulation}

Factors influencing the pressure relief effect of blasting include rock parameters, blasting parameters and explosive parameters etc. To simplify the simulation, the surrounding rock conditions of the roadway (Table 1) and explosive parameters are kept unchanged. Under certain conditions of borehole diameter, charge length, borehole spacing and decouple coefficient, changing the hole depth to explore the relationship between hole depth and the size of released range. The numerical simulation scheme determined by the condition above is shown in Table 2. 
Table 1. Mechanical parameters of rocks.

\begin{tabular}{ccccccc}
\hline Position & Lithology & $\begin{array}{c}E \\
(\mathrm{Gpa})\end{array}$ & $\mu$ & $\begin{array}{c}\rho \\
\left(\mathrm{kg} / \mathrm{m}^{3}\right)\end{array}$ & $\begin{array}{c}C \\
(\mathrm{MPa})\end{array}$ & $\begin{array}{c}\varphi \\
\left({ }^{\circ}\right)\end{array}$ \\
\hline Roof & Sandstone & 15.5 & 0.26 & 2450 & 3.6 & 25 \\
Sidewalls & Coal & 7.4 & 0.23 & 2210 & 2.5 & 20 \\
Floor & Mudstone & 5.3 & 0.21 & 2420 & 2.2 & 20 \\
Smash zone & Coal & 0.8 & 0.25 & 2210 & 1.5 & 16 \\
Fractured zone & Coal & 1.48 & 0.24 & 2210 & 1.9 & 18 \\
Stemming & Clay & 0.7 & 0.28 & 2130 & 1.2 & 15 \\
\hline
\end{tabular}

Table 2. Numerical simulation scheme.

\begin{tabular}{ccccc}
\hline Hole Depth/m & Hole Diameter/mm & Decoupling Coefficient & Charge Length $/ \mathrm{m}$ & Hole Spacing $/ \mathrm{m}$ \\
\hline 4 & 50 & 1.2 & 2 & 3 \\
5 & 50 & 1.2 & 2 & 3 \\
6 & 50 & 1.2 & 2 & 3 \\
7 & 50 & 1.2 & 2 & 3 \\
8 & 50 & 1.2 & 2 & 3 \\
\hline
\end{tabular}

To facilitate analysis and comparison, different models are numbered according to schemes and parameters of numerical simulation. Numbering of numerical models are A4, A5, A6, A7, A8, where 4, 5, 6, 7, 8(m) means the hole depth.

\subsection{Path Extraction of Modeling Data}

To extract the data that can reflect the stress and convergence deformation law of roadway surrounding rock before and after the destressing blasting, two analysis paths were set, and 65 monitoring points were arranged on each path.

Path 1, is a horizontal section line along the middle of roadside shown in Figure 2(a), and is used to monitor the stress change from the surface of the roadway to a depth of $13 \mathrm{~m}$ of the surrounding rock. The tangential stress, and Mises stress of surrounding rock are extracted and analyzed. For sidewall, tangential stress $\sigma_{\theta}$ is $\sigma_{\gamma}$, radial stress $\sigma_{\gamma}$ is $\sigma_{x}$.

Path 2, as shown in Figure 2(b), is a vertical section line which is perpendicular to Path 1, and is used to monitor and extract the deformation of the surrounding rock on roadway surface from the corner point of roadway roof to the corner point of roadway floor.

By comparing the deformation of roadway sides and surface surrounding rock before and after destress blasting, stress map and displacement map of roadway surrounding rock under different pressure relief parameters are drawn, and the variation law of each data is analyzed. Thus, the internal relationship between each blasting parameter and blasting pressure relief effect is determined, and the purpose of guiding the on-site destress blasting construction has achieved.

\section{Results and Discussions}

According to the simulation scheme in Table 2, the simulation process involves 


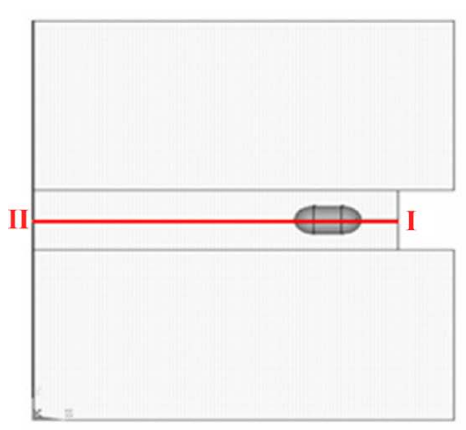

(a)

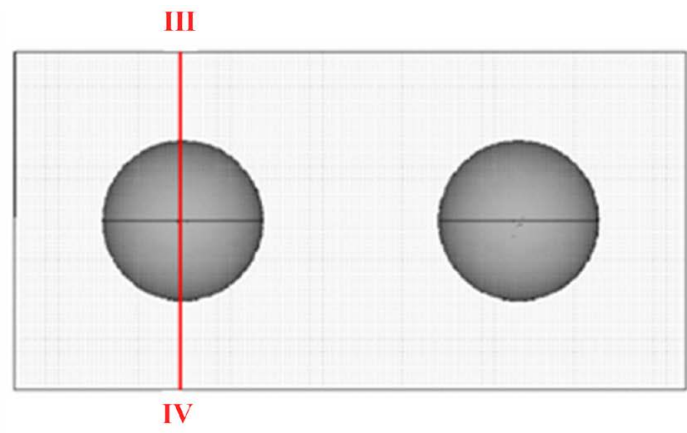

(b)

Figure 2. Data analysis paths. (a) Path 1; (b) Path 2.

five factors: hole depth, hole diameter, decoupling coefficient, charge length and hole spacing. With different hole depths, $\sigma_{\theta}, \sigma_{\gamma}$ and deformation of surface surrounding rock are extracted from each model. Each data has 65 monitoring points.

\subsection{Analysis of Blasting Pressure Relief Effect and Pressure Relief Range}

When the hole depth is $4 \mathrm{~m}$, the hole diameter is $50 \mathrm{~mm}$, the charge length is 2 $\mathrm{m}$, the decoupling coefficient is 1.2 and the hole spacing is $3 \mathrm{~m}$, Stress layout of side walls before and after destress blasting are shown in Figure 3.

Following analyses are concluded from Figure 3:

1) Before the blasting, when $\mathrm{r}=2.0 \mathrm{~m}, \sigma_{\theta}$ reaches a maximum of 39.54 $\mathrm{MPa}$. When $\mathrm{r}>2.0 \mathrm{~m}, \sigma_{\theta}$ decreases gradually to $22.61 \mathrm{Mpa}$ then tends to be stable as $r$ increases. After the blasting, $\sigma_{\theta}$ exhibits a bimodal distribution, the first peak value is $27.48 \mathrm{MPa}$ when $\mathrm{r}=1.0 \mathrm{~m}$. the second peak value is $31.07 \mathrm{MPa}$ when $\mathrm{r}=4.8 \mathrm{~m} . \sigma_{\theta}$ is reduced from $39.54 \mathrm{MPa}$ to $27.47 \mathrm{MPa}$ which unloading efficiency is $30.51 \%$.

2) Before the blasting, when $\mathrm{r}=2.8 \mathrm{~m}, \sigma_{\gamma}$ reaches a maximum of 13.45 $\mathrm{MPa}$. After the blasting, $\sigma_{\gamma}$ also exhibits a bimodal distribution, the first peak value is $6.57 \mathrm{MPa}$ when $\mathrm{r}=1.0 \mathrm{~m}$. The second peak value is $13.60 \mathrm{MPa}$ when $\mathrm{r}=$ $4.8 \mathrm{~m} . \sigma_{\gamma}$ is reduced from $13.45 \mathrm{MPa}$ to $6.85 \mathrm{MPa}$ which unloading efficiency is $49.07 \%$.

3) When $\mathrm{r}$ is between $1.0 \mathrm{~m}$ and $4.8 \mathrm{~m}$, both $\sigma_{\theta}$ and $\sigma_{\gamma}$ decrease dramatically after the blasting, thus, this zone is viewed as stress relief zone, and the width of stress relief zone is about $3.8 \mathrm{~m}$.

4) After the blasting, the high stress zone shift from the zone of $1.0 \mathrm{~m}<\mathrm{r} \leq 2.0$ $\mathrm{m}$ to the zone of $\mathrm{r} \geq 4.8 \mathrm{~m}$.

\subsection{Analysis of the Relationship between Hole Depth and Destress Blasting Effect}

According to the schemes in Table 2, stress distributions of models from A4 to A 8 before and after the blasting are shown in Figure 4. 


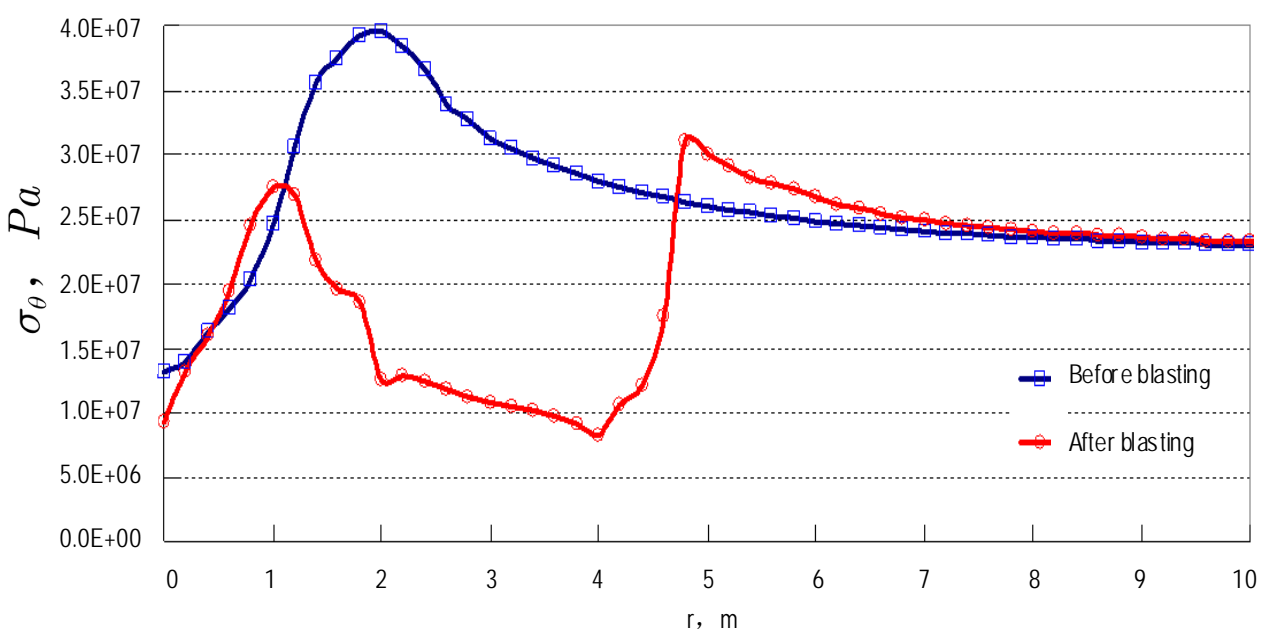

(a)

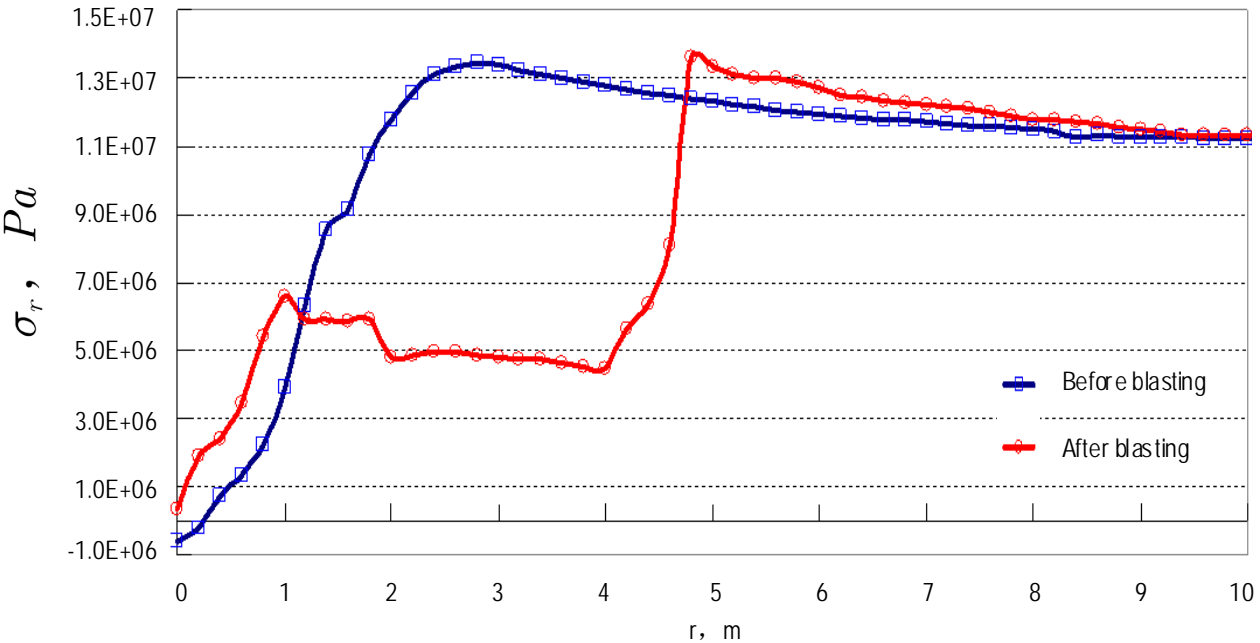

(b)

Figure 3. Stress layout of side walls before and after destress blasting. (a) Stress distribution of $\sigma_{\theta}$; (b) Stress distribution of $\sigma_{\gamma}$.

Following analysis are concluded from Figure 4:

1) After the blasting, when the hole depth increases from $4 \mathrm{~m}$ to $8 \mathrm{~m}$, peak stress's depth shifts from $4.8 \mathrm{~m}$ to $8.8 \mathrm{~m}$, while the width of stress relief zone is still around $3.8 \mathrm{~m}$. Peak stress $\sigma_{\theta}$ 's reduce degree is $30.51 \%, 7.5 \%, 15.1 \%, 16.2 \%$ and $15.45 \%$. Peak stress $\sigma_{\gamma}$ 's reduce degree is $49.07 \%, 8.92 \%, 0 \%, 5.2 \%$ and $15.45 \%$. Obviously, the optimal hole depth should be $4 \mathrm{~m}$.

2) The width of high stress pillar in the shallow surrounding rocks increases from $1 \mathrm{~m}$ to $3 \mathrm{~m}$ as hole depth increases from $4 \mathrm{~m}$ to $8 \mathrm{~m}$. It can be concluded that an over wide high stress zone is not good for the stability of roadway.

Therefore, the optimal destressing effect is achieved when the borehole depth is $4 \mathrm{~m}$. The high-stress could be transferred to the deeper surrounding rock by increasing the blast hole depth but the pressure reduction effect of the surrounding rock in the shallow tunnel is not obvious, and this is not conducive to the stability of the tunnel. 


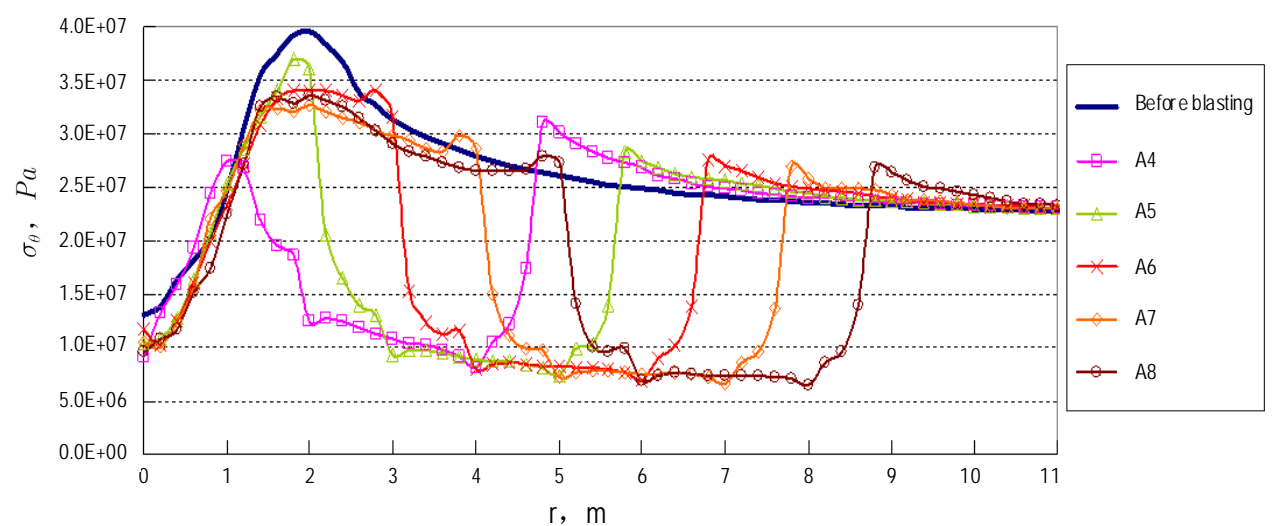

(a)

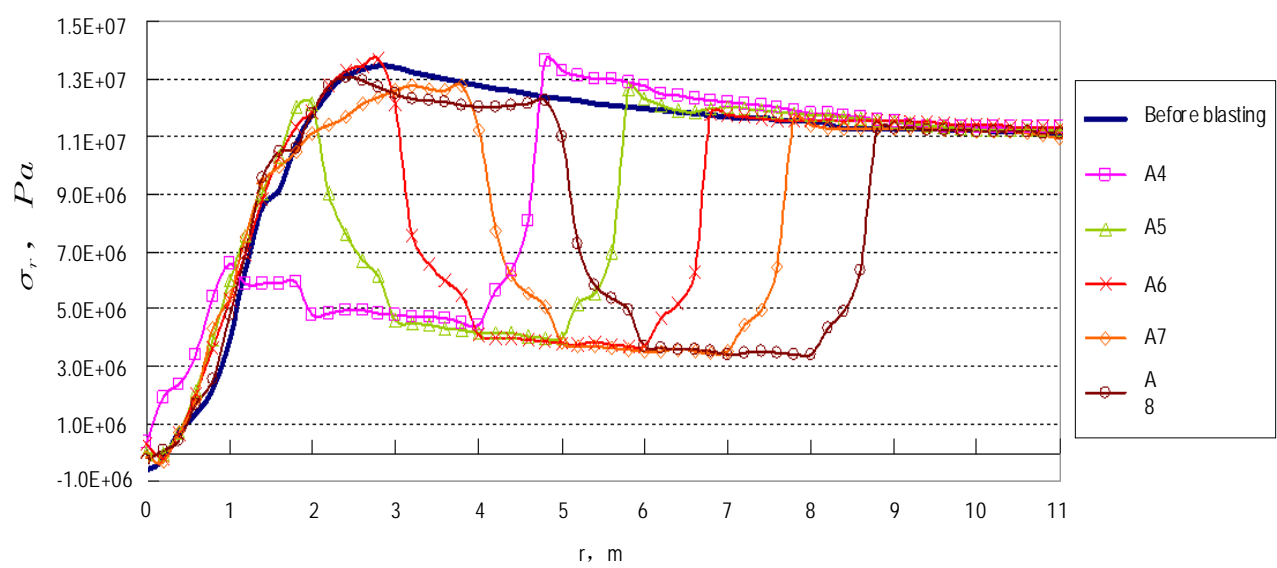

(b)

Figure 4. Stress layout of side walls with different depths of blast holes before and after destress blasting. (a) Stress distribution of $\sigma_{\theta}$ with different hole depths; (b) Stress distribution of $\sigma_{r}$ with different hole depths.

\section{Conclusions}

In this paper, numerical simulations have been carried out to analyze the destress blasting effect in a quantitative manner, and multiple parameters have been taken into consideration. The following conclusions could be drawn:

1) The optimal blasting hole depth is $4 \mathrm{~m}$. Under this setting, $\sigma_{\theta}$ 's reduce degree can reach $49.07 \%, \sigma_{\gamma}$ 's reduce degree can reduce $30.51 \%$.

2) When the hole depth increases from $4 \mathrm{~m}$ to $8 \mathrm{~m}$, peak stress's depth shifts from $4.8 \mathrm{~m}$ to $8.8 \mathrm{~m}$, and a $3.8 \mathrm{~m}$ wide stress relief zone is formed.

Because there are many factors that affect the effect of pressure relief blasting, and because of the transient response, complexity and anisotropy of rock, it is undoubtedly more difficult to study the mechanism of pressure relief. The research in this paper is only a preliminary attempt in the quantitative research of blasting pressure relief technology, but also needs further research and exploration combined with field test. We have reason to believe that through unremitting efforts, we can find reliable theoretical support for the application of blasting pressure relief technology in deep roadway support. 


\section{Acknowledgements}

This work was supported by The Fundamental Research Funds for the Central Universities (2017XKQY050).

\section{Conflicts of Interest}

The authors declare no conflicts of interest regarding the publication of this paper.

\section{Referencesg}

[1] Sainoki, A., Emad, M.Z. and Mitri, H. (2017) Study on the Efficiency of Destress Blasting in Deep Mine Drift Development. Canadian Geotechnical Journal, 54, 518-528. https://doi.org/10.1139/cgj-2016-0260

[2] Konicek, P., Soucek, K., Stas, L., et al. (2013) Long-Hole Destress Blasting for Rockburst Control during Deep Underground Coal Mining. International Journal of Rock Mechanics and Mining Sciences, 61, 141-153. https://doi.org/10.1016/j.ijrmms.2013.02.001

[3] Mazaria, A. and Konicek, P. (2015) Intense Rockburst Impacts in Deep Underground Construction and Their Prevention. Canadian Geotechnical Journal, 52, 1426-1439. https://doi.org/10.1139/cgj-2014-0359

[4] Wojtecki, M.M.J. and Zuberek, W.M. (2016) The Seismic Source Parameters of Tremors Provoked by Destress Blastings in Coal Seam. Journal of Mining Science, 52, 258-264. https://doi.org/10.1134/S1062739116020382

[5] Guo, W.-Y., Zhao, T.-B., et al. (2017) Progressive Mitigation Method of Rock Bursts under Complicated Geological Conditions. International Journal of Rock Mechanics and Mining Sciences, 96, 11-22. https://doi.org/10.1016/j.ijrmms.2017.04.011

[6] Ptáček, J., Konicek, P., Staš, L., Waclawik, P. and Kukutsch, R. (2015) Rotation of Principal Axes and Changes of Stress Due to Mine-Induced Stress. Canadian Geotechnical Journal, 52, 1440-1447. https://doi.org/10.1139/cgj-2014-0364

[7] Song, H.H. and Wei, H. (2015) Application of Blasting Destressing Technology in Preventing and Controlling Rock Burst in Deep Coal Seam. China Coal, 41, 53-56.

[8] Zhao, K., Gu, S.J., Zhou, K.P., Zhao, H.Y., Yan, Y.J., Li, Q. and Zhu, S.T. (2016) Relationship between Characteristics of Geostress for Deep Mining District and Mining-Induced Seismicity. Electronic Journal of Geotechnical Engineering, 21, 7033-7044.

[9] Yang, G.Y., Jiang, F.X. and Wang, C.W. (2014) Prevention and Control Technology of Mine Pressure Bumping of Coal Mining Face in Seam Island Based on Deep Mining and Thick Topsoil of Complex Spatial Structure of Overlying Strata. Chinese Journal of Geotechnical Engineering, 36, 189-194.

[10] Wang, T., You, S., Pei, F., et al. (2017) Instability Mechanism and Control Technology of Coal Pillar Bumps under Hard Roof. Journal of Mining and Safety Engineering, 34, 54-59+ 66 .

[11] Sun, W.F., Bian, X.C., Qi, X.Y., Zhang, B., et al. (2014) Research of Rockburst Prediction and Control Technology. Applied Mechanics and Materials, 577, 1127-1130. https://doi.org/10.4028/www.scientific.net/AMM.577.1127

[12] Łukasz, W., Konicek, P., Mendecki, M.J. and Zuberek, W.M. (2017) Application of Seismic Parameters for Estimation of Destress Blasting Effectiveness. Procedia Engineering, 191, 750-760. https://doi.org/10.1016/j.proeng.2017.05.241 
[13] Meng, Q.B. (2013) Research on Deep Soft Rock Roadway Support Technology and Engineering Examples. Proceedings of National Symposium on Mining Technology for Kilometers Deep Coal Well, Tai'an, 25 July 2013, 166-171.

[14] Zhao, S.K., Deng, Z.G., Qi, Q.X. and Li, H.Y. (2016) Theory and Application of Deep Hole Floor-Break Blasting in Floor Rock Burst Coal Mine. Rock Mechanics and Rock Engineering. From the Past to the Future, 1, 511-516.

https://doi.org/10.1201/9781315388502-87

[15] Tian, J.S. and Jing, H.W. (2010) Blasting to Relieve Pressure around a Soft Rock Roadway. Journal of China University of Mining \& Technology, 39, 50-54.

[16] Chen, S.F., Liu, D.S. and Wang, S.R. (2006) Static Photo-Elastic Experiment Study on Maintenance of Roadway with Relieving Blasting. Journal of Liaoning Technical University, 25, 873-875.

[17] Gao, Q.C., Zhou, B., Chen, S.F., Shi, Z.W., et al. (2006) Safety Technology of Destress Blasting in High Stress Rock Drifts of Coal Mine. Progress in Safety Science and Technology, 6, 1772-1776.

[18] Zhang, X.Y., Tu, M. and Yang, K. (2009) Pressure Releasing Technology with Borehole Drilling and Blasting for Mine Roadway in High Stressed Strata. Coal Science and Technology, 37, 74-77.

[19] Zhang, P. (2007) Experimental Study on Repairing Roadway with Anchor Grouting and Blasting. Journal of Huainan Vocational \& Technical College, No. 3, 4-6.

[20] Zhao, G. (2008) Experiment Study on Repairing Laneway by Way of Bolting and Blasting to Relieve Laneway Pressure in Xieqiao Coal Mine. Coal Technology, No. 7, 121-123.

[21] Guo, X.S. and Wang, J.Z. (2013) Application of Pressure-Relief by Blasting in Deepseated High Ground Stressed Roadway Support. China Mine Engineering, 42, $22-25+29$.

[22] Wang, S., Zhong, Z.L., et al. (2019) D-P Yield Criterion Based Elastoplastic Solution of the Circular Pressure Tunnel. Modern Tunneling Technology, 56, 74-80.

[23] Xiong, Z.Q. and He, H.J. (2006) Numerical Simulation of Rock Burst Stress and Its Control by Stress-Relief. Journal of Mining \& Safety Engineering, 23, 489-493. 